\title{
IDENTIFICATION OF THE COMPONENTS BY LCMS/MS- QTOF AND TOXICITY OF ETHANOL EXTRACTS OF Musa paradisiaca L. STEMS
}

\author{
Mayang Sari ${ }^{1}$ and Erni Misran ${ }^{2, \varpi}$ \\ ${ }^{1}$ Faculty of Pharmacy and Health, Institut Kesehatan Helvetia, Kapten Sumarsono Street 107, \\ Medan, Sumatera Utara, Indonesia \\ ${ }^{2}$ Department of Chemical Engineering, Universitas Sumatera Utara, Jl. Almamater, Padang \\ Bulan, Medan 20155, Indonesia \\ ${ }^{\square}$ Corresponding Author: erni2@usu.ac.id
}

\begin{abstract}
Banana plants from the Musaceae family thrive in tropical countries, especially in Indonesia, with various types and one of them is Musa paradisiaca Linn (MPL). Banana is an important horticultural plant considering its high productivity and take place regardless the season. Various parts of banana plants such as flower, fruit, leave, stem, and tuber can be utilized as food. Chemical constituents of ethanol extract of MPL stem were identified and characterized by LCMS/MS-QTOF. Based on the results of MS fragmentation, MPL extracts contained 10 components which were Mubenoside A; 25 (R) - Ruscogenin -1-O- $\beta$-D-glucopyranosyl (1 $\rightarrow 2)$ - $\beta$-Dfucopyranoside; Oleanolic acid 3-O- $\beta$-D-xylopyranosyl- $(1 \rightarrow 2)$ - $\alpha$-L-arabinopyranosyl-28-O- $\beta$-D glucopyranosyl$(1 \rightarrow 6)$ - $\beta$-D glucopyranoside; Raddeanoside; Baicalein-6-glucuronide; Undulatoside A; 26-Deoxyactein; Methyl ophiopogonone A; Ginsenoside Rh4; Eclalbasaponin VIII. These constituents were found to be compounds with known medicinal activity. A toxicity test was performed by Brine shrimp lethality bioassay. The toxicity properties of ethanol extract of MPL showed $\mathrm{LC}_{50} 894.46 \mathrm{ppm}$
\end{abstract}

Keywords: Banana, Musa Paradisiaca L, LCMS/MS-QTOF, Oleanolic Acid, Medicinal, Toxicity.

RASĀYAN J. Chem., Vol. 14, No.2, 2021

\section{INTRODUCTION}

Banana plants can thrive in tropical and sub-tropical areas. These plants can grow with the diversity of species in Indonesia with its tropical climate. Banana plants can produce throughout the year, regardless the season. Indonesia is one of the largest banana producing countries with various varieties. ${ }^{1}$ One of the superior varieties is Musa Paradisiaca Linn (MPL). All parts of the banana plant have many benefits, one of which is its stem. From previous studies, Musa Paradisiaca L stems consist of several secondary metabolites, such as alkaloids, steroids like $\beta$-sitosterol, saponins, flavonoids. ${ }^{2}$ Banana pseudo stem extracts also contain terpenoid compounds, cardiac glycoside, steroids, alkaloid saponins, tannins, and flavonoids. ${ }^{3}$ The presence of these metabolite compounds is a signal that extracts has the potential to be developed as a medicine. So far, all parts of the plant have also been used traditionally to treat diarrhea, dysentery, diabetes, hypertension, spur, uremia, nephritis, gout, heart disease, and anti-fungal. 4,5

Thus we will report the bioactive components of the ethanol extract of MPL stem from North Sumatera, Indonesia and its toxicity properties.

\section{EXPERIMENTAL}

\section{Plant Material and Extraction}

Stems of MPL with a diameter of 15-20 cm were collected from Deli Serdang District, North Sumatera. The stems were rinsed with water and cut into thin slices. The thin slices were dried and powdered. Subsequently, the powder of MPL was extracted using $96 \%$ ethanol by the maceration method. The ethanol extract of MPL stem was then characterized. 
RASĀYAN J. Chem.

Vol. 14 | No. 2 |1330-1335| April - June | 2021

\section{Preparation of LCMS / MS-QTOF Characterization Test Samples}

A total of $0.5 \mathrm{~g}$ of MPL stem ethanol extract was dissolved in $10 \mathrm{~mL}$ methanol, sonicated for 30 minutes and homogenized. The mixture was filtrated using a $0.22 \mu \mathrm{m}$ a GHP/PTFE membrane filter. Then a total of $10 \mu \mathrm{L}$ was injected into the UPLC system.

\section{QT-OF Conditions}

The QT-OF uses a binary solvent delivery system, namely $0.1 \%$ formic acid and $0.1 \%$ formic acid in acetonitrile. Agilent Poroshell 120 EC-C18 Column Chromatography $(3.0 \times 50.0 \mathrm{~mm}, 2.7 \mu \mathrm{m})$ at $40^{\circ} \mathrm{C}$ column temperature. Detection by PDA (photodiode array detection) at 180-380 nm, Hyster autosampler $\left(15^{\circ} \mathrm{C}\right)$ was used. The sample volume was $10 \mu \mathrm{L}$ with detection of positive and negative ions $(\mathrm{m} / \mathrm{z})$ between 50-1200 Da. The UNIFI software can identify the mass spectrum of a compound, which is adapted to the mass spectrum in the library.

\section{Brine Shrimp Lethality Bioassay}

Hatching of Artemia salina Leach cyst for 48 hours, and toxicity activity test was carried out at 3 concentrations of extract solution of $10,100,500 \mathrm{ppm}$ and the addition of $20 \mathrm{~mL}$ of seawater. Testing was conducted by entering 30 shrimp larvae. As control is seawater that is not given a sample extract. The number of shrimp larvae that died was counted after 1 day of adding the extract as a percentage to determine the $\mathrm{LC}_{50}$ value which gave a $50 \%$ mortality rate due to the effect of the extract. ${ }^{6-8}$

\section{LCMS/MS-QTOF Investigation}

\section{RESULTS AND DISCUSSION}

The ethanol extract of MPL stem samples were analyzed using LCMS/MS-QTOF with UNIFI Software that can identify the mass spectrum of compounds in the sample. There were 10 compounds which matched to the library of tools on a negative ESI and a positive ESI as listed in Table-1.

The interesting thing in this work is that all of the identified compounds in MPL stem extracts are known to have some biological activity. Previous studies of these bioactive compounds include the mechanism of the compound Ruscogenin and Radix Ophiopogon japonicus as anti-inflammatory and vascular disorders. ${ }^{9}$

Table-1: Compounds of Extracts MPL stems analyzed by LCMS/MS-QTOF

\begin{tabular}{c|l|c|c|c}
\hline ESI & \multicolumn{1}{|c|}{ Proposed Compound Identity } & $\begin{array}{c}\text { Molecular } \\
\text { Formula }\end{array}$ & $\begin{array}{c}\text { Retention } \\
\text { Time (RT) }\end{array}$ & $\begin{array}{c}\text { Mass } \\
\text { Accuracy } \\
(\mathrm{ppm})\end{array}$ \\
\hline+ & Mubenoside A & $\mathrm{C}_{45} \mathrm{H}_{72} \mathrm{O}_{17}$ & 13.13 & -3.79 \\
\hline+ & $\begin{array}{l}25(\mathrm{R})-\text { Ruscogenin-1-O- } \beta-D \text { glucopyranosyl }(1 \rightarrow 2)-\beta-\mathrm{D}- \\
\text { fucopyranoside }\end{array}$ & $\mathrm{C}_{39} \mathrm{H}_{62} \mathrm{O}_{13}$ & 13.14 & -3.50 \\
\hline+ & $\begin{array}{l}\text { Oleanolic acid 3-O- } \beta-D-x y l o p y r a n o s-y l-(1 \rightarrow 2)-\alpha-\mathrm{L}- \\
\text { arabinopyranosyl-28-O- } \beta-D-g l u c o p y r a n o s y l-(1 \rightarrow 6)-\beta-D- \\
\text { glucopyranoside }\end{array}$ & $\mathrm{C}_{52} \mathrm{H}_{84} \mathrm{O}_{21}$ & 16.46 & -0.41 \\
\hline+ & Raddeanoside R7 & & \\
\hline+ & Baicalein-6-glucuronide & $\mathrm{C}_{53} \mathrm{H}_{86} \mathrm{O}_{21}$ & 16.65 & -0.45 \\
\hline+ & Undulatoside A & $\mathrm{C}_{21} \mathrm{H}_{18} \mathrm{O}_{11}$ & 0.54 & 0.24 \\
\hline+ & $26-$ Deoxyactein & $\mathrm{C}_{16} \mathrm{H}_{18} \mathrm{O}_{9}$ & 0.54 & 3.88 \\
\hline- & Methyl ophiopogonone A & $\mathrm{C}_{37} \mathrm{H}_{56} \mathrm{O}_{10}$ & 4.92 & 4.92 \\
\hline- & Ginsenoside Rh4 & $\mathrm{C}_{19} \mathrm{H}_{16} \mathrm{O}_{6}$ & 14.94 & -3.56 \\
\hline- & Eclalbasaponin VIII & $\mathrm{C}_{36} \mathrm{H}_{60} \mathrm{O}_{8}$ & 17.93 & 3.90 \\
\hline
\end{tabular}

Fruits and vegetables containing oleanolic acid, a triterpenoid pentacyclic type, have potential for therapeutic purposes in various diseases. ${ }^{10}$ Some of the pharmacological activities of oleanolic acid are antiinflammation, antioxidant, antitumor, anticancer, ${ }^{11-13}$ and hepatoprotector. ${ }^{14}$ Biological activity of oleanolic acid and its derivatives include antidiabetes ${ }^{15}$ and antimicrobes. ${ }^{16}$ 
RASĀYAN J. Chem.

Vol. 14 | No. 2 |1330-1335| April - June | 2021

Plants containing raddeanoside have antitumor, antimicrobial, antiinflammatory activities. ${ }^{18,9}$ Baicalin (baicalein 7-O-glucuronide) has anti-allergy, anti-inflammatory, and antioxidant activity and is also used as a treatment for hepatitis, hyperlipidemia and lipolysis. ${ }^{19}$

Plants that contain major constituents, one of which is undulatosides, are used in the treatment of diabetes. ${ }^{20}$ The use of 26-Deoxyactein triterpenoid tetracyclic compounds at low levels of the Cimicifuga foetida $L$. rhizome showed a significant antitumor activity. ${ }^{21}$

Methylophiopogonanone compounds contained in the biological activity of Radix Ophiopogonis Japonici include low oral bioavailability $(5 \%-19 \%)$ and can treat CVD (cardiovascular disease). ${ }^{22}$ Previous studies indicated that one of the active ingredients of Methylophiopogonanone A in Radix Ophiopogonis was used in the treatment of hepatitis B sufferers with liver fibrosis. ${ }^{23}$

Herbal medicine (ginseng) which has main constituents of ginsenosides and their derivatives is proven to be active as an antiinflammation. ${ }^{24}$ Eclalbasaponin plants Eclipta prostrate, and extracts from these plants have potential antidiabetic activity and do not show hepatotoxicity. ${ }^{25}$

\section{Item name: 191202 _911 $R$ 6026__ Pos}

Channel name: Integrated : Smoothed : Background Subtracted : 1: TOF MSe BPI (50-1200) 6eV ESI+

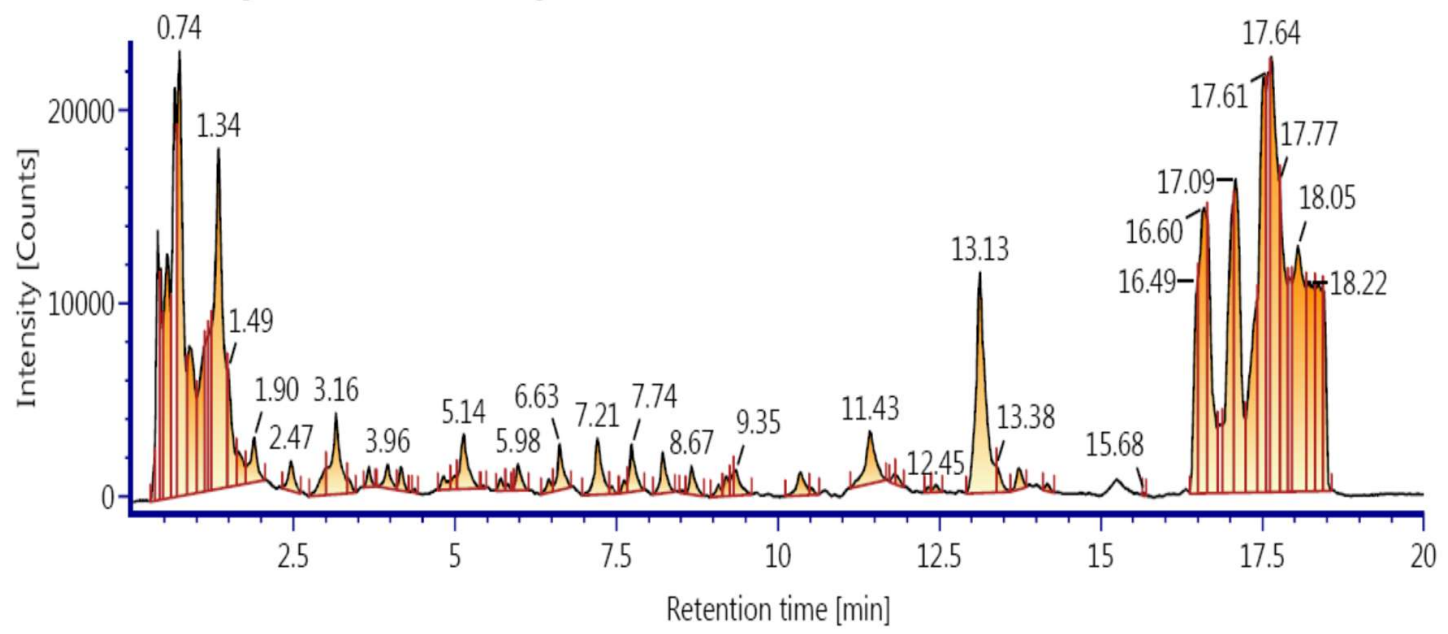

Fig.-1: The LC Chromatograms (ESI+) of Ethanol Extract of MPL Stems

Item name: 191202 _ $911 \mathrm{R} 6026 \_1$ Neg

Channel name: Integrated : Smoothed : Background Subtracted : 1: TOF MSe BPI (50-1200) 6eV ESI-

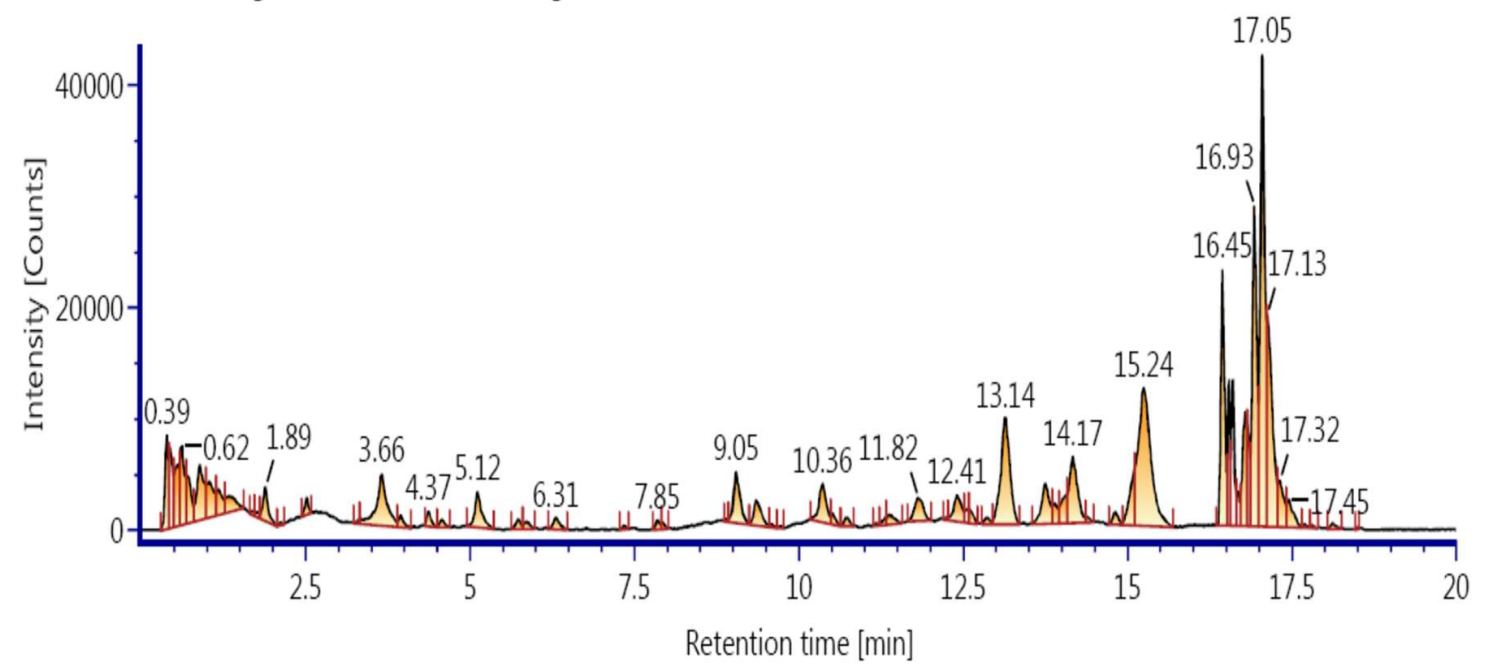

Fig.-2. The LC Chromatograms (ESI-) of Ethanol Extract of MPL Stems 
RASĀYAN J. Chem.

Vol. 14 | No. 2 |1330-1335| April - June | 2021

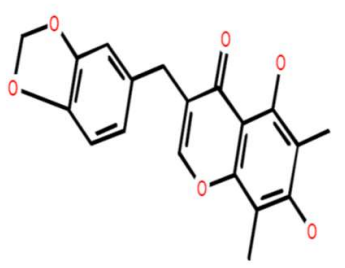

(a)

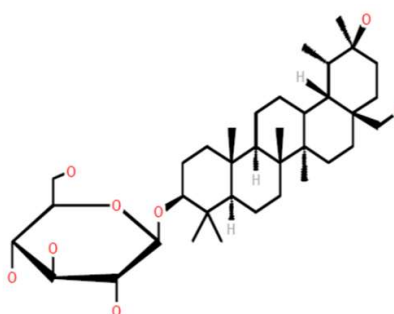

(b)

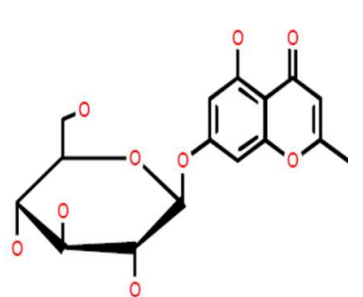

(c)

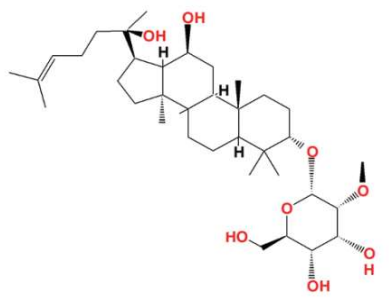

(d)

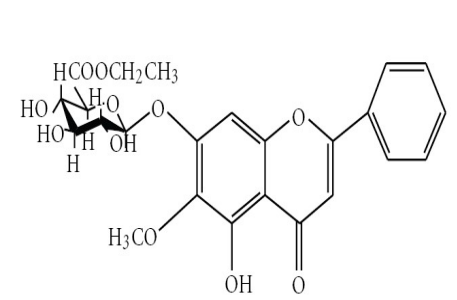

(e)

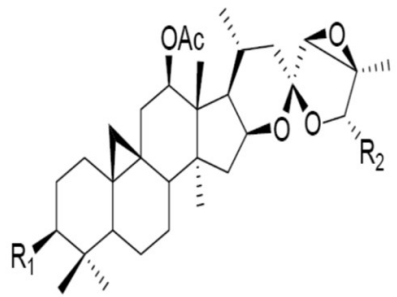

(f)

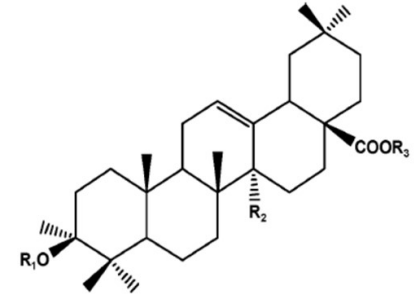

$(\mathrm{g})$
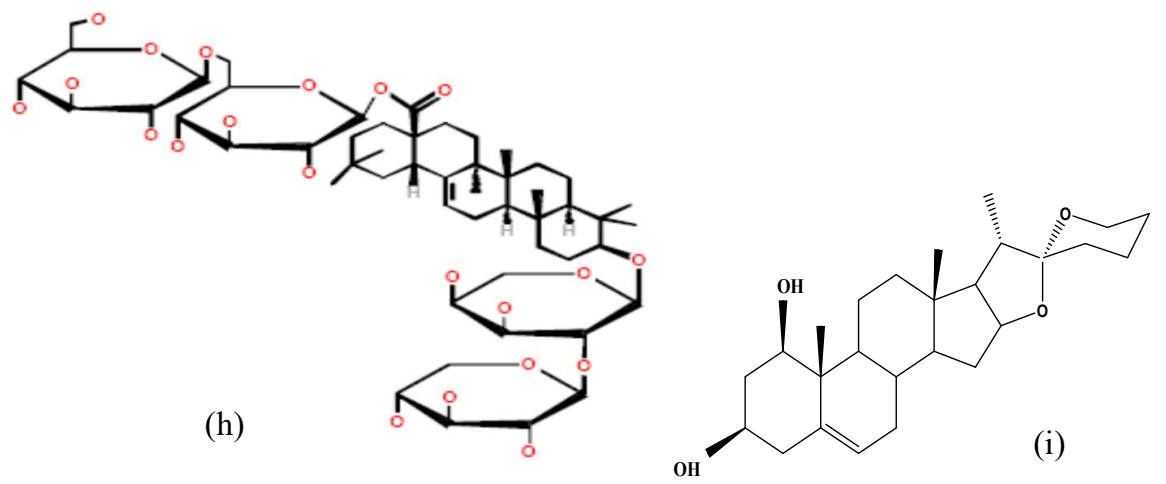

Fig.-3: The Structure of the Compound was identified from Ethanol Extract of MPL: (a) Methyl ophiogonone A (b) Eclalbasaponinn VIII (c) Undulatoside A (d) Ginsenoside (e) Baicalein (f) 26-deoxyactein; $\mathrm{R}_{1}=\mathrm{OXX}_{\mathrm{X}} ; \mathrm{R}_{2}=\mathrm{H}$ (g) Raddeanosida R7; $\mathrm{R}_{1}=\beta$-D-Glc $(1 \rightarrow 2)$ - $\alpha$-L-Ara; $\mathrm{R}_{2}=\mathrm{CH}_{3} ; \mathrm{R}_{3}=\alpha$-L-Rha(1 $\left.\rightarrow 4\right)$ - $\beta$-D-Glc (h) Oleanolic acid 3O- $\beta$-D-xylopyranos-yl-( $1 \rightarrow 2)-\alpha$-L- arabinopyranosyl-28-O- $\beta$-D-glucopyranosyl $(1 \rightarrow 6)-\beta$-D-glucopyranoside (i)

\section{Toxicity Activity}

Ruscogenin

Toxicity values with BSLT showed that the ethanol extract of MPL stem gave a mortality percentage with $\mathrm{LC}_{50} 894.46 \mathrm{ppm}$. The observations for the percentage of mortality of shrimp larvae are presented in Table-2.

Table-2: Toxicity of Ethanol Extract of Musa paradisiaca L Stem

\begin{tabular}{c|c|c|c|c|c}
\hline \multirow{4}{*}{$\begin{array}{c}\text { Ethanol Extract of } \\
\text { MPL Stem }\end{array}$} & $\begin{array}{c}\text { Extract Concentration } \\
(\mathrm{ppm})\end{array}$ & $\begin{array}{c}\text { Total of } \\
\text { Larva }\end{array}$ & $\begin{array}{c}\text { Amount of } \\
\text { Dead Larva }\end{array}$ & $\begin{array}{c}\text { Mortality } \\
(\%)\end{array}$ & LC $_{50}(\mathrm{ppm})$ \\
\cline { 2 - 6 } & 10 & 30 & 7 & 23.33 & \\
\cline { 2 - 6 } & 100 & 30 & 8 & 26.66 & 894.46 \\
\cline { 2 - 6 }
\end{tabular}

The pure component of eclalbasaponin has an $\mathrm{LC}_{50}$ value of $16.21-17.78,{ }^{26}$ which is categorized as very toxic according to the classification of toxicity Meyer et al. ${ }^{6,27}$ While the MPL stem extract contained eclalbasaponin compounds with $\mathrm{LC}_{50}$ value of 894.46, which was classified in the moderate category. Bioassay method of saltwater shrimp lethality as an initial method in detecting bioactive in extract samples to determine the development of extracts from an ingredient used in predicting the cytotoxic, antitumor, and pesticide activities of the extract. Presumably, these compounds are Oleanolic Acid, Raddeanoside, Baicalein 7-O-glucuronide, 26-deoxyactein, Methylophiopogonanone A, and Eclalbasaponin based on previous literature. 
RASĀYAN J. Chem.

Vol. 14 | No. 2 |1330-1335| April - June | 2021

\section{CONCLUSION}

Some active compounds can be found in the stem of Musa Paradisiaca Linn, which is rarely used after harvesting. It turns out that plant stems can be a source of useful medicinal ingredients. This research has shown that there are useful drug agents in the stem of MPL extract which need to be exploited.

\section{ACKNOWLEDGEMENT}

The authors thank to LPDP and Universitas Sumatera Utara for supporting this research.

\section{REFERENCES}

1. M. Sari, Tamrin, J. Kaban and Z. Alfian, Rasayan Journal of Chemistry, 13(4), 2508(2020), DOI:10.31788/RJC.2020.1345802

2. K. Lavanya, World Journal Pharmaceutical and Medical Research, 2(6), 163(2016)

3. C.T. Onyema, C. Ofor, V. Okudo and A. Ogbuagu, Phytochemical Journal of Pharmaceutical Researsh, 10(1), 1(2016), DOI: 10.9734/bjpr/2016/22593

4. M.Z. Imam and S. Akter, Journal of Applied Pharmaceutical Science, 1(5), 14 (2011)

5. S.I. Okorondu, C.O. Akujobi and I.N. Nwachukwu, International Journal of Biological and Chemical Sciences, 6(4), 1527(2012), DOI:10.4314/ijbcs.v6i4.12

6. G. Saragih and D.Y. Nasution, Rasayan Journal of Chemistry, 13(1), 476(2020), DOI:10.31788/RJC.2020.1315524

7. D.G.R. Aruan, T. Barus, G. Haro and P. Simanjuntak, Rasayan Journal of Chemistry, 12(1), 947 (2019), DOI:10.31788/RJC.2019.1225204

8. R. Hardiyanti and L. Marpaung, AIP Conference Proceedings, 2049, 030015(2018), DOI: $10.1063 / 1.5082516$

9. Y. L. Huang, J. P. Kou, L. Ma, J.X. Song and B.Y. Yu, Journal of Pharmacological Sciences, 108(2), 198 (2008), DOI:10.1254/jphs.08083FP

10. T.B. Ayeleso, M.G. Matumba and E. Mukwevho, Journal of Molecules, 22(11), 1915 (2017), DOI:10.3390/molecules22111915

11. X. Wang, R. Liu, W. Zhang, X. Zhang, N. Liao and Z. Wang, Journal of Molecular and Cellular Endocrinology, 376(1-2), 70 (2013), DOI:10.1016/j.mce.20133.06.014

12. X. Song, C.C. Liu, Y.R. Hong and X.C. Zhu, Journal of the Bangladesh Pharmacological Society, 10(4), $896(2015)$

13. S.R. Yoo, S.J. Jeong, N.R. Lee, H.K. Shin, C.S. Seo, Pharmacognosy Magazine, 13(51), 339 (2017), DOI:10.4103/0973-1296.211023

14. G.A. Gutiérrez-Rebolledo, A.G. Siordia-Reyes, M. Meckes-Fischer and A. Jiménez-Arellanes, Asian Pacific Journal of Tropical Medicine, 9(7), 644 (2016), DOI:10.1016/j.apjtm.2016.05.015

15. A. Mukundwa, S. Mukaratirwa and B. Masola, Journal of Diabetes, 8(1), 98(2016), DOI:10.1111/1753-0407.12260

16. S. Kim, H. Lee, S. Lee, Y. Yoon and K.H. Choi, Journal of PLoS One, 10(3), 1(2015), DOI:10.1371/journal.pone.0118800

17. R. Martín, C. Cordova, J.A. San Román, B. Gutierrez, V. Cachofeiro and M. Nieto, Journal of Molecular and Cellular Cardiology, 72, 250(2014), DOI:10.11018/j.yjmcc.2014.04002

18. E. Mongelli, A.B. Pomilio, J.B. Sánchez, F.M. Guerra and G.M. Massanet, Phytotherapy Research, 16(4), 387(2002), DOI: 10.1002/ptr.955

19. Y. Wang, J. Yang, X. Li and J. Wang, Journal of Evidence-based Complement Alternative Medicine, 2012, 1(2012), DOI:10.1155/2012/404529

20. S. Kumar, S. Sharma, N. Vasudeva and V. Ranga, Journal of Diabetology and Metabolic Syndrome, 4(1), 1(2012), DOI:10.1186/1758-5996-4-33

21. D. Wu, Q. Yao, Y. Chen, X. Hu, C. Qing and M. Qiu, Journal of Molecules, 21(8), 1001(2016), DOI:10.3390/molecules21081001

22. X. Wang, X. Xu, W. Tao, Y. Li, Y. Wang and L. Yang, Journal of Evidence-based Complement Alternative Medicine, 2012(2), DOI:10.1155/2012/519031

23. G. Li, Y Zhou, D.M.Y. Sze, C. Liu, Q. Zhang, Z. Wang, Journal of Evidence-based Complement 


\section{RASĀYAN J. Chem.}

Vol. 14 | No. 2 |1330-1335| April - June | 2021

Alternative Medicine, 2019, 1 (2019), DOI:10.1155/2019/2408126

24. J.H. Kim, Y.S. Yi, M.Y. Kim and J.Y. Cho, Journal of Ginseng Research, 41(4), 435(2017), DOI:10.1016/j.jgr.2016.08.004

25. M.S. Rahman, M.Z. Rahman, B. Begum, R. Chowdhury, S.N. Islam and M.A. Rashid, Latin American Journal of Pharmacy, 30(8), 1656(2011), DOI:10.1066/s-0028-1084319

26. M.S. Rahman and M.A. Rashid, Journal of Oriental Pharmacy and Experimental Medicine, 8(1), 47(2008), DOI:10.3742/opem.2008.8.1.047

27. B.N. Meyer, N.R. Ferrigni, J.E. Putnam, L.B. Jacobsen, D.J. Nichols and J.L. McLaughlin, Journal of Planta Medica, 45(05), 31 (1982), DOI:10.1055/s-2007-971236

[RJC-5969/2020] 